\title{
ÊNFASE NAS RELAÇÕES INTERPESSOAIS NA FORMAÇÃO DO ENFERMEIRO SOB O PARADIGMA ÉTICO-HUMANISTA
}

\author{
EMPHASIS ON INTERPERSONAL RELATIONS IN THE BASIC TRAINING OF NURSES \\ IN THE ETHICAL-HUMANISTIC PARADIGM
}

Josiane Bernart da Silva Ferla ${ }^{1}$

Resumo Este estudo analisa a formação inicial do enfermeiro e seu vínculo com o paradigma ético-humanista, especialmente as relações interpessoais. Adotou-se na pesquisa a abordagem qualitativa, do tipo descritivo-exploratório. Os sujeitos eram egressos e docentes do curso de enfermagem de uma faculdade particular da cidade de Curitiba, no Paraná. A coleta de dados foi feita em 2009, com utilização das técnicas de análise documental do projeto pedagógico do curso de graduação em enfermagem, aplicação de questionário aos egressos da graduação em enfermagem e entrevista semiestruturada realizada com enfermeiros-docentes. As informações coletadas foram submetidas à análise de conteúdo, da qual emergiram três categorias: totalidade/multidimensionalidade; interdisciplinaridade/disciplinaridade/dicotomia teoria-prática; relações interpessoais/competência interpessoal. Os resultados revelam que tanto docentes como discentes percebem a formação acadêmica ainda centrada nos referenciais técnico-científicos, porém com uma intencionalidade real de formação também de competências voltadas às relações humanas. Este estudo permitiu identificar a influência do paradigma ético-humanista proposto pelas diretrizes curriculares no processo de formação do enfermeiro, além de reforçar a necessidade de novas possibilidades de desdobramentos das ideias capazes de se fundamentarem em princípios pedagógicos que visem à totalidade do ser em formação e do ser assistido pelo profissional da saúde. Palavras-chave educação; enfermagem; paradigma ético-humanista; relações interpessoais
Abstract This study assesses on the early training of nurses and its relationship with the ethical-humanistic paradigm, especially to interpersonal relationships. A descriptive-exploratory qualitative research approach was used. The subjects were graduates and professors in nursing in the city of Curitiba, southern Brazil. The data were collected in 2009, using documentary analysis techniques for the undergraduate nursing program's educational project, the application of a questionnaire among graduates of the college of nursing, and semi-structured interviews conducted among nursing professors at a private college. The data collected were subjected to content analysis, from which three categories emerged: totality/multidimensionality; interdisciplinarity/disciplinarity/dichotomy between theory and practice, interpersonal relations/ interpersonal skills. The results show that both faculty and students realize that the academic training provided is still focused on technical and scientific references, but with a real intent to provide training in skills aimed at human relations. This study allowed the influence of the ethical and humanistic paradigm proposed by the curricular guidelines in the nursing education process to be noted, and reinforced the need for new possibilities to develop ideas capable of serving as the base for educational principles aimed at the totality of being in training and of the person assisted by a health professional.

Keywords education; nursing ethical and humanistic paradigm; interpersonal relationships. 


\section{Introdução}

Nos dias de hoje, um aprofundamento acerca das práticas educativas em enfermagem se faz necessário, uma vez que a realidade e o cotidiano demonstram que devemos ir além do processo de ensino e aprendizagem. É preciso transcender uma concepção de formação de um ideário profissional em enfermagem que não condiz com a realidade humana e social vivenciada.

O ensino na enfermagem, como processo educativo, desde sua institucionalização vem passando por várias transformações na busca da competência profissional, procurando acompanhar o desenvolvimento técnico-científico e sendo influenciado pelas condições sociopolíticas e culturais em várias épocas. Nesse cenário, as relações interpessoais conquistam espaço na medida em que auxiliam no cuidado em diferentes níveis de complexidade, em que o enfermeiro torna-se um agente de mudanças capaz de interagir e intervir com e na sociedade, motivado pela transformação pessoal, profissional e social.

Segundo Mizukami (1986), há várias formas de se conceber o processo educativo. Nele estão presentes as dimensões humanas: a técnica, a cognitiva, a emocional, a sociopolítica e a cultural. Não se trata, portanto, de mera justaposição das referidas dimensões, mas sim da aceitação de suas múltiplas implicações e relações, bem como da utilização destas na prática profissional.

A necessidade de um profissional crítico surge dos questionamentos quanto à ruptura do tecnicismo voltado ao modelo biomédico e ao retorno às práticas de cuidado, porém com um enfoque ético-humanista. Tal premissa encontra base nas palavras de Demo (1990), que afirma que o profissional não é aquele que executa sua profissão, mas, sobretudo, aquele que sabe pensar e refazer sua profissão, na incessante construção do conhecimento. O mesmo autor enfatiza a reflexão acerca da formação em face das transformações do novo século, em que os educadores passaram a rever seus pressupostos teóricos, baseando-se em desígnios norteadores de um ideário profissional. Esta formação é detentora de possíveis desdobramentos para as práticas pedagógicas, em cuja proposta assistencial encontramos a humanização como grande apelo no sentido de proporcionar consonância nas abordagens relacionadas ao ensino em enfermagem.

Em tal perspectiva, trata-se, portanto, de direcionar o acadêmico ao 'para quê' e 'para quem' tal capacidade de crítica e de construção do conhecimento será utilizada, e não, meramente, de ampliar a criatividade do aluno e do professor em relação ao conhecimento como dimensão crítica do saber, sem considerar o ser cuidado e o ser cuidador.

A formação acadêmica com ênfase em um paradigma ético e humanista é a responsável por fortalecer o indivíduo e mostrá-lo ao mundo, com toda a competência que se espera de um profissional que saiba lidar com situa- 
ções e conflitos que eventualmente possam aparecer. Para tanto, é vital que percebamos o mundo que nos cerca, que despertemos o sentido crítico, a curiosidade intelectual e o desenvolvimento da capacidade para comunicar, especialmente na interação socioprofissional no trabalho em enfermagem, que visa proporcionar ao profissional enfermeiro saberes inerentes às relações interpessoais e competências interpessoais.

A abordagem educativa em vigor, especialmente no que se refere ao currículo de graduação em enfermagem, e por que não dizer em outras áreas da saúde, parece-nos desafiadora em relação aos níveis de realidade e de percepção. Como expõe Berger (2001), o grande desafio da educação deste século está em aliar o desenvolvimento científico e tecnológico à expansão da consciência do ser humano sobre as dimensões pessoais e transpessoais de sua existência e seu papel como cidadão planetário.

Estamos vivendo um momento histórico permeado por um acelerado processo de modernização científica e tecnológica que nos desafia, como edu-cadores, a (re)pensar a educação integral do ser humano, uma vez que somos impulsionados a protagonizar novas formas de construção de conhecimento que nos instigam a dar respostas para além da capacidade técnica especializada e científica habitual. Esse modelo é meramente técnico e científico, cristalizado sob a égide de um paradigma cartesiano que não mais atende às necessidades de um mundo globalizado.

Tal dinâmica de relação entre homem, natureza e sociedade, portanto, está sujeita à abertura de novos caminhos à educação, o que nos remete a repensar o processo educativo em uma abordagem ética e humanista, dessa forma favorável a possíveis transformações com vistas a uma prática pedagógica voltada à totalidade desse ser humano. Um ser que é fisiológico, constituído em sistemas e passível de 'reparos', 2 sim, mas também social, capaz de suscitar interações e relações consigo mesmo e com seus semelhantes, como numa complexa teia de relacionamentos que pressupõem a existência de algo mais do que simplesmente um corpo, uma máquina ou um 'quebra-cabeça' que pode ser montado e desmontado quando bem convier.

Apesar da conformidade acerca da aceitação da relevância do tema relações interpessoais no ensino, não se observa coerência entre esse fato e o ensino real que se processa na maioria das instituições formadoras de enfermeiros. A concepção ético-humanista, bem como a dita competência interpessoal, em todas as suas vertentes é algo ainda pouco vislumbrado e, portanto, é pouco praticada. Parece, pois, segundo Souza (2004), que a humanidade percebeu, de repente, que deu demasiada importância às máquinas, à tecnologia, à informação, esquecendo-se da constituição do ser humano.

Nesse contexto, o processo de formação acadêmica do enfermeiro envolve como finalidade a promoção de mudanças nos indivíduos, mudanças essas desejáveis e relativamente permanentes, as quais implicam tanto a aquisição 
de novos comportamentos quanto a modificação dos já existentes. No tocante às relações que se estabelecem entre os seres, Cortelazzo (2001) assinala que é por meio da colaboração mútua que se formam os sujeitos coletivos, se constroem novos conhecimentos, se agregam valores ao conhecimento já existente, se tecem novas teias de conexões que aumentam a aprendizagem.

Mizukami (1986) acrescenta que é importante ressaltar que tudo que estiver a serviço do crescimento pessoal, interpessoal ou intergrupal é educação. Portanto, os elementos de ensino, aluno, professor e conteúdo, devem ser vistos de forma equitativa. Não se deve perder o foco na prática da vida, no mundo do trabalho e na cidadania como necessidades humanas indispensáveis no compromisso da transformação social e profissional do enfermeiro.

De acordo com Schirr (2006), aprender, ensinar e conviver são desafios do século atual, pois as pessoas estão em busca de raízes e referências e necessitam aprender a viver juntas nesse mundo globalizado, onde a educação emerge como grande trunfo, por possibilitar o desenvolvimento contínuo de pessoas e, consequentemente, da sociedade.

Salientamos, ainda, a importância atribuída ao nosso estudo com vistas à compreensão de um paradigma ético-humanista cuja essência permeia princípios que são norteadores das diretrizes de formação do profissional enfermeiro. Tais diretrizes visam possibilitar o repensar a natureza do homem, como ser individual e coletivo, suas capacidades e potencialidades, bem como suas relações, no intuito de contextualizar o conhecimento apreendido às ações desejadas no processo de cuidar em saúde.

Este estudo, portanto, desenvolveu-se com o intuito de identificar a influência do paradigma ético-humanista proposto pelas diretrizes curriculares no processo de formação do enfermeiro, caracterizando aspectos da trajetória da profissionalização da enfermagem, descrevendo os pressupostos teórico-metodológicos que orientam a formação inicial em enfermagem e caracterizando a compreensão dos alunos e professores deste curso sobre o significado atribuído ao paradigma ético-humanista e, dentro dele, as relações interpessoais no processo de formação do enfermeiro.

Diante da amplitude desses objetivos, optou-se por desenvolver neste artigo os marcos das relações interpessoais durante o percurso histórico da enfermagem como profissão e a discussão sobre o paradigma ético-humanista no ensino.

\section{Metodologia}

A metodologia adotada segue os princípios da pesquisa qualitativa por envolver o universo humano, uma vez que, segundo Ludke e André (1986), esta possibilita a apreensão de aspectos subjetivos do objeto de estudo, aqui 
retratado como as relações interpessoais, implicando a obtenção de dados descritivos e, portanto, propiciando um contato mais próximo com o contexto investigado, na tentativa de compreender a perspectiva dos sujeitos participantes do estudo. Dessa forma, optou-se por utilizar as técnicas de entrevista semiestruturada com a aplicação de questionário, atreladas à pesquisa documental do projeto pedagógico do curso de enfermagem.

A pesquisa foi desenvolvida em uma instituição privada de ensino superior, mantida por uma entidade de caráter filantrópico, religioso, educacional e sem fins lucrativos. Os sujeitos do estudo foram divididos em dois grupos: egressos do curso de graduação em enfermagem e enfermeiros-docentes da graduação em enfermagem, todos da mesma instituição.

O grupo de egressos, a princípio, foi composto por enfermeiros formados pela instituição de ensino superior nos anos de 2006 e 2007, perfazendo uma população total de 81 indivíduos, para os quais os questionários foram enviados. Desta população total, a análise se fez no quantitativo de cinco questionários, que foram devolvidos devidamente preenchidos. A delimitação desses anos deve-se ao fato de que se trata dos primeiros enfermeiros formados pela instituição com o novo currículo, o qual ancora-se nos princípios ético-humanistas propostos pelas diretrizes curriculares nacionais (DCNs) (CNE, 2001), referencial desta investigação. O grupo de docentes-enfermeiros perfazia um total de 18 indivíduos, cujo quantitativo amostral permaneceu em seis indivíduos.

Para sua viabilização, destaca-se que os aspectos éticos seguiram a resolução n. 196/96 do Conselho Nacional de Saúde, que estabelece diretrizes e normas éticas da pesquisa que envolve seres humanos (Brasil, 1996). Baseando-se nesta resolução, após aprovação do projeto pelo Comitê de Ética e Pesquisa sob o protocolo n. 2009-007525 e certificação de Apresentação para Apreciação Ética (CAAE) sob o n. 7525/09, foi solicitada a autorização dos sujeitos participantes (egressos e docentes), com assinatura de um termo de consentimento livre e esclarecido.

A coleta de dados foi realizada no ano de 2009 em basicamente três etapas, por meio das seguintes técnicas: pesquisa documental no projeto pedagógico do curso de graduação em enfermagem; aplicação de questionário aos egressos da graduação em enfermagem; entrevista semiestruturada com os enfermeiros-docentes.

Há que salientar que as informações obtidas pela pesquisa documental no projeto pedagógico do curso de graduação em enfermagem, a aplicação de questionário aos egressos da graduação e as entrevistas semiestruturadas realizadas com enfermeiros docentes, representadas, em sua análise, pela letra $\mathrm{P}$ maiúscula - referente a professor e um número cardinal sequenciado no sentido de individualizar o sujeito da pesquisa -, foram submetidas à análise de conteúdo de Bardin (1977, p. 105), que “consiste em descobrir os núcleos 
de sentido que compõem a comunicação e cuja presença ou frequência de aparição podem significar alguma coisa com o objetivo analítico escolhido".

\section{Paradigma ético-humanista no ensino de enfermagem}

A enfermagem, ao longo dos tempos, foi se aperfeiçoando técnica e cientificamente. A sobrevida dos enfermos, a estrutura tecnológica, as práticas cada vez mais estruturadas, a complexidade do corpo cada vez mais explorado e desvendado fizeram com que a idolatria da técnica tornasse a enfermagem extremamente eficiente, porém bem menos humana no sentido do cuidado e das relações interpessoais. O cuidado técnico passou a ser essencial, assim como as atividades voltadas exclusivamente ao tratamento e à cura, deixando, por sua vez, lacunas que se refletem também no processo de formação e na condução da prática no campo profissional.

Dessa forma, estabelecer, entender e proporcionar relações mais humanas e éticas implica compromisso, uma responsabilidade - segundo Waldow (2001) - de estar no mundo e não fazer apenas aquilo que satisfaz ou é moralmente correto, mas ajudar a construir uma humanidade pautada em princípios e valores que deveriam fazer parte não só do ensino, mas do cotidiano acadêmico.

Nessa perspectiva, temos um modelo de racionalidade emergente pautada no que muitos consideram como paradigma. Quanto ao que pode ser compreensível acerca de paradigmas, tal palavra é comumente empregada tendo como referência as 'ciências', porém vem sendo cada vez mais utilizada nos diversos argumentos e discussões, de cunho filosófico ou, até mesmo, espiritual.

Kuhn (2007) se refere a paradigma como um modelo ou um padrão aceito, ou ainda como as realizações científicas que são universalmente reconhecidas e que, durante algum tempo, são capazes de fornecer problemas e soluções que servem de modelo para uma comunidade de praticantes de uma determinada ciência.

De forma gradual, esse conceito vem permeando nosso cotidiano e despertando novas indagações. Assim, a importância desses paradigmas não se resume meramente aos padrões da ciência, mas está de tal forma arraigado em nosso ser, por meio de valores e regras, que sequer tomamos conta de sua existência.

Levando, pois, em consideração o rompimento de um paradigma cartesiano e a emergência de um paradigma aqui considerado como ético-humanista, torna-se pertinente uma citação de Campos (2003, p. 124): "Humano quer dizer humano, ou seja, biológico, subjetivo e social (...). Somos isso o tempo todo, misturado, inseparável, ao mesmo tempo." Interes- 
sante pensar que mesmo antes do florescer do pensamento cartesiano a doutrina médica, na qual a enfermagem sempre esteve pautada, entendia o corpo como um instrumento de percepção e de ação controlado pelos desejos, valores e emoções e que, após o afastamento da filosofia do homem, passou a ser, segundo Campos (2003), relegada ao limbo. Nesse momento, para a autora, o saber médico passou a rejeitar tudo que estivesse relacionado à subjetividade humana.

Entretanto, na segunda metade do século XX, a própria ciência passou a anunciar a transição das verdades e doutrinas, de forma que o saber médico revela-se, em diversificados momentos, precário em relação ao reconhecimento e à compreensão dos referenciais e princípios humanos descartados e esquecidos há séculos, ou seja: a ciência não mais consegue sustentar fatos de maneira meramente objetiva, como outrora fazia. Há, pois, uma real necessidade de se levar em consideração também a subjetividade inserida nos fatos.

Nesse cenário, impregnado pelo pragmatismo, o ensino de enfermagem se desenvolve, porém tal abordagem conservadora que acompanhou a docência e a atividade profissional por muito tempo, baseando-se numa visão fragmentada dos fenômenos da natureza e, portanto, em um discurso pedagógico dominante, passa a necessitar da construção de uma consciência pessoal e profissional que, segundo Kruse (2008), serve de princípio para a prática, de critério para a crítica e consequentemente de transformação dessa prática. Transformação esta não entendida aqui como reflexão na ação, baseando-se na racionalidade técnica, como nos propõe autores teóricos como Donald Schon (2000), mas como transformação da prática, seja ela de docência, seja de atividade profissional, embasada por conhecimentos científicos que a sustentem e garantam sua efetividade, conhecimentos esses adquiridos durante o processo de formação.

A racionalidade técnica, conforme citado, não se refere necessária e exclusivamente a Donald Schon, mas à razão técnica que, de acordo com Ghedin (2002), consiste numa epistemologia da prática que deriva da filosofia positivista, defendendo a ideia de que os profissionais solucionem problemas instrumentais mediante critérios dos meios técnicos, ou seja, o conhecimento é sempre obtido por meio de uma relação estabelecida entre a prática e as interpretações que fazemos dela.

Em consonância com o exposto, faz-se necessário mencionar, acerca da filosofia positivista, que nos referimos à medicina moderna ou científica como aquela fundamentada na anatomia patológica dentre outras disciplinas ou conteúdos que permitiram e privilegiaram a manipulação do corpo de forma individualizada. Ciência esta que passa a predominar, segundo Geovanini et al. (2005), no período de desorganização-organização das relações sociais e econômicas da ordem feudal para a capitalista, podendo, de acordo com 
esses autores, ser grosseiramente caracterizada pela mudança na pergunta “o que você tem?", proposta pelo médico ao paciente, para "onde lhe dói?" (Geovanini et al., 2005, p. 136). Assim, diante de sua fundamentação na anatomia patológica, na fisiologia, na biologia e em outras ciências, a medicina descobre no corpo enfermo a localização do mal que o encobre, através de um olhar clínico, detentor de um direito irrefutável da verdade, comprovado cientificamente numa relação de causa e efeito concreta e mensurável.

Nesse contexto, a visão conservadora e reducionista da ciência biomédica possibilitou a proposição de aprendizagens focadas em verdades consideradas absolutas e inquestionáveis. Para Behrens e Gisi (2006), o paradigma tradicional, ou seja, pragmático, traduzido como uma abordagem mecânica do universo, fez-se acompanhar por abordagens educativas que, ao longo do tempo, tiveram como foco central a reprodução de saberes técnicos em detrimento de conhecimentos científicos. Kruse (2008), ao analisar as técnicas como o primeiro saber organizado e sistematizado da enfermagem, observou-as muito mais voltadas à realização da tarefas como a arrumação e o controle do ambiente, o que acabou por produzir um esquadrinhamento do tempo e do espaço, ou seja, uma procura minuciosa em que o corpo é controlado e trabalhado detalhadamente nos seus gestos e atitudes.

Como afirma Camargo (1996), a pessoa humana, anteriormente concebida como sujeito do processo terapêutico, respeitada em sua dignidade, vontade, razão e liberdade, por ora transforma-se em objeto de estudos, consumidora de tecnologia. A supervalorização do cientificismo implica capitulações graves no que concerne à atitude humanista, tendo em vista que os avanços científicos e tecnológicos vivenciados nas últimas décadas vêm ocorrendo 'desnudos de qualquer reflexão ética'.

Torna-se cada vez mais comum, especialmente em instituições formadoras de recursos humanos em saúde, nos depararmos com cobranças políticas e sociais, no sentido de alcançar uma formação que possibilite o estabelecimento de relações ético-humanistas mais fortalecidas. Tais relações requerem uma atuação profissional pautada no 'cuidado' com o ser humano, baseando-se no acolhimento, no vínculo e no respeito.

Ainda que as razões para a necessidade de uma (re)significação do perfil do profissional de saúde, no sentido de buscar relações mais éticas e humanizadas, tenham um sentido mais profundo e subjetivo, observamos razões sociais mais objetivas atualmente apontadas por meio das DCNs. Tal perspectiva pode ser observada por meio das exigências das políticas públicas de educação - além do atual programa de humanização da atenção aos usuários do Sistema Único de Saúde (HumanizaSUS) - e, obviamente, da competitividade do mercado de trabalho, o qual tem exigido posturas relacionais mais qualificadas no que concerne aos profissionais da área de saúde, aqui mencionados os enfermeiros como sujeitos do nosso estudo. 
Não obstante, Matos (2006) afirma que se faz necessário estar ciente de que o perfil ético-humanista de um profissional de saúde produz e se manifesta mediante uma abordagem multidimensional, na qual o indivíduo está integrado em uma teia de relações. Entendemos, desse modo, que contribui para esse perfil uma interação complexa de vários sistemas, tais como a família, a espiritualidade, a escola, os referenciais psicossocioculturais do indivíduo e o conhecimento técnico científico sobre áreas de humanidades e de determinantes psicossociais do processo saúde-doença.

Pautando nossa discussão numa posição epistemológica antipositivista, optamos por subsidiar nossa discussão baseados na perspectiva do teórico Boaventura de Sousa Santos, que põe em causa a teoria representacional da verdade e a primazia das explicações causais, defendendo a ideia de que todo o conhecimento científico é socialmente construído, que o seu rigor tem limites inultrapassáveis e que a sua objetividade não implica a sua neutralidade.

A ciência não descobre, cria, e o acto criativo protagonizado por cada cientista e pela comunidade científica no seu conjunto tem de se conhecer intimamente antes que conheça o que com ele se conhece do real. Os pressupostos metafísicos, os sistemas de crenças, os juízos de valor não estão antes nem depois da explicação científica da natureza ou da sociedade. São parte integrante dessa mesma explicação. A ciência moderna não é a única explicação possível da realidade e não há sequer qualquer razão científica para a considerar melhor que as explicações alternativas da metafísica, da astrologia, da religião, da arte ou da poesia. A razão por que privilegiamos hoje uma forma de conhecimento assente na previsão de que no controle dos fenômenos nada tem de científico. É um juízo de valor. A explicação científica dos fenômenos é a autojustificação da ciência enquanto fenômeno central da nossa contemporaneidade. A ciência é, assim, autobiográfica (Santos, 2008, p. 83-84).

Em consonância com o exposto, ressaltamos aqui um conceito de paradigma exposto por Kuhn (2007, p. 220), como sendo aquele que "indica toda a constelação de crenças, valores, técnicas, etc., partilhadas pelos membros de uma comunidade determinada". Dessa forma, portanto, temos que os paradigmas permeiam todas as instituições que compõem uma determinada sociedade.

Nesse intuito, Santos (2008) nos faz refletir sobre a distinção dicotômica entre ciências naturais e ciências sociais, que deixou de ter sentido e utilidade, uma vez que se assenta numa concepção mecanicista da matéria e da natureza a que contrapõe, como pressuposta evidência, os conceitos de ser humano, cultura e sociedade.

Corroborando o que nos diz o autor supracitado, cuja vertente volta-se à educação, Moraes (1997) salienta que a forma como a educação é desenvolvida traduz a percepção e o conhecimento de teorias de aprendizagem implícitas e subjacentes às proposições utilizadas, com sérias consequências no 
desencadeamento da prática pedagógica. Portanto, uma mudança paradigmática em saúde implica também o oferecimento de uma prática pedagógica com vistas à totalidade, cuja responsabilidade e preocupação estão em proporcionar as relações contempladas numa teia complexa, e que pressupõem entender a existência de conexões em um contexto de transformação.

Dessa forma, entende-se que um paradigma não sofre transformações à medida que se impõe uma nova roupagem, obscurecendo teorias antigas. Mas é necessário que a cognição humana seja ampliada e norteada por um referencial teórico que direcione a busca de uma nova abordagem, um novo paradigma capaz de conciliar a ciência aos avanços científicos e tecnológicos com a necessidade hodierna de construção e reconstrução contínua do homem, do mundo e do homem no mundo.

Discute-se aqui, portanto, o estado atual das práticas educativas relativas à saúde, em especial ao ensino da enfermagem, dada a visão fragmentária do ser humano, proveniente de um modelo biomédico instituído historicamente e que reduz o indivíduo a um corpo técnico, passivo e objeto de intervenções, cujo horizonte de referência é excluído da dimensão totalizante do ser humano. Ressalta-se ainda que, embora os princípios humanistas da assistência sejam defendidos, especialmente no que se refere à enfermagem, há muito tempo, podemos perceber que são pouco experienciados no cotidiano do ensino acadêmico.

Berger (2001) nos convida a pensar novamente acerca do que estamos vivendo hoje, como educadores comprometidos com a formação integral do ser individual, em uma realidade humano-social. Por conseguinte, entendemos a necessidade, corroborando o que diz esse autor, de ultrapassar a noção meramente instrumental da educação, considerada como direção obrigatória para obtenção de determinados resultados, como o de aprender a fazer e adquirir competências e habilidades diversificadas em detrimento de fins econômicos, e passar a considerá-las em toda a sua plenitude, ou seja, integrar o saber ao ser.

As situações de doença ou questões administrativas do posto de saúde eu encaminho ou discuto com o próprio posto de saúde. Já as demais questões eu encaminho para outros setores, principalmente a assistência social. Os encaminhamentos costumam seguir uma formalidade e respeitar os fluxos institucionais, mas sempre há encaminhamentos informais, que desrespeitam os fluxos, pois são mais rápidos e eficazes (SC1, SC2, SS2, SS3, SS4, SS5, SR1, SR3, SR4).

\section{O paradigma ético-humanista no curso de enfermagem}

Numa sociedade movida pelas aceleradas e profundas revoluções científicas, culturais e tecnológicas, não se podem ignorar as contradições e incertezas, as 
dominações e alienações nela existentes, nem desconsiderar a falta de uma política educacional e econômica definida em prol do desenvolvimento humano em suas múltiplas dimensões. Dentro desse cenário importa redimensionar o sentido dessas transformações, realizando análise e reflexão do processo educativo acompanhadas de ações construtivas que produzam mudanças (Zanette, 2003, p. 80).

No tocante ao projeto político-pedagógico do curso de enfermagem da faculdade particular em estudo, podemos dizer que este se aproxima de interesses e pressupostos previstos nas diretrizes curriculares - diretrizes essas norteadoras de sua elaboração - e busca, por meio de seus marcos referenciais e matriz curricular, uma formação de agentes transformadores da realidade em um contexto de integralidade.

Ainda que possamos entender a necessidade de uma (re)significação do perfil do profissional enfermeiro, no sentido de buscar relações mais éticas e humanizadas, observamos que atitudes, ou melhor, razões mais objetivas têm sido apontadas. Dentre elas, destacamos a exigência das políticas públicas de educação, por meio das diretrizes curriculares nacionais, além da própria competitividade do mercado de trabalho que busca posturas relacionais como mais uma referência de competência profissional. E aqui, mais uma vez, destacamos a importância das relações interpessoais como alicerce para essa proposta de formação.

Quanto ao projeto pedagógico da instituição em estudo, este propõe uma perspectiva integradora à ação pedagógica, uma vez que suscita um projeto interdisciplinar capaz de substituir o produzir e transmitir conhecimento por uma proposta de ampliação da visão de mundo, do ser e da sociedade. Contudo, mesmo visando a uma nova proposta de construção curricular e, portanto, de formação, nos deparamos ainda com a ótica de um sistema educacional marcado pela fragmentação do conhecimento.

No intuito de favorecer nossa análise, apresentamos o marco referencial que integra o projeto pedagógico proposto pela instituição em estudo, aliado às considerações pertinentes. Quanto à estrutura deste marco referencial, podemos observar sua divisão por meio de três dimensões: marcos conceituais, teóricos e sistematizadores, cada qual fundamentado em bases conceituais que embasam o perfil do egresso desejado no seu processo de formação.

Com relação ao marco conceitual, a questão principal está voltada a que alunos se pretende formar, tendo como pano de fundo bases da filosofia, da sociologia e da psicologia. Nessa parte do projeto pedagógico, encontramos os preceitos propostos pelas DCNs em consonância com as teorias do ensino por competências ou pedagogia das competências, voltados ao aprender-conhecer, aprender-fazer, aprender-conviver e aprender-intervir. Trata-se, pois, de referências aos princípios pedagógicos que foram se incorporando 
e que hoje permeiam o currículo de formação em enfermagem, cujo foco está voltado ao aluno, tendo o docente como facilitador desse processo.

Em contraponto, temos o marco teórico que nos apresenta formas de conceber a formação desejada. Interessante ressaltar que, ao pontuar tais aspectos relacionados a conteúdos, metodologia e métodos avaliativos, o marco teórico encontra-se em dissonância com referência ao marco conceitual, uma vez que apresenta, especialmente no item metodologia, a relação transmissora e condicionada de conteúdos, embora aliados à problematização e salvaguardados por princípios de totalidade, teoria-prática, diversidade e complexidade.

Entendemos, assim, que se trata de não secundarizar a aquisição de conhecimentos, mas de agregá-los ao saber sistematizado, científico e tecnológico como integrantes nucleares para a formação desse profissional, não sendo possível abrir mão de saberes oriundos de outras áreas de conhecimento, mas de fazer avançar o cuidado e o entendimento humano como centrais na assistência à saúde.

Com relação ao marco sistematizador, este se refere à forma de integrar linhas de ação no campo institucional. Assim, diversas estratégias são traçadas, como o modo de estruturar as disciplinas, a preocupação com a articulação destas em forma de eixos integralizadores divididos em áreas temáticas que propõem, em cada fase do curso, suplantar as necessidades de formação de um sujeito múltiplo, ético e com responsabilidade social, além de um profissional consistente, no que se refere ao processo de trabalho, apto a desenvolver o cuidado qualificado almejado.

O sistema educacional brasileiro tem passado por diversas mudanças nos últimos tempos - segundo Schmidt (2003), mudanças necessárias e provocadas pela implementação da lei n. 9.394/96 (Brasil, 1996a) e sua regulamentação. Em meio a tantas transformações, faz-se mister relembrar que fruto disso é o currículo, constituindo este o fundamento de qualquer sistema de ensino e o elemento nuclear do projeto pedagógico. Podemos, portanto, entender que se trata de conexões entre o que é ensinado e o que é aprendido numa sociedade que foi sendo modificada e reestruturada ao longo dos tempos, perpassando diversas possibilidades de entendimento do processo educacional, ora assumindo posições mais conservadoras, ora demonstrando atitudes mais renovadoras.

É nesse sentido que analisamos o projeto pedagógico do curso de enfermagem de uma instituição particular da cidade de Curitiba, no Paraná, no intuito de entender em que medida posições mais conservadoras - aqui consideradas como disciplinares e pautadas apenas na emissão de conteúdos - ou renovadoras - voltadas ao pensamento mais crítico, problematizador e ético - são apresentadas objetivamente. 
Entendemos, pois, que tal proposta pedagógica do curso de graduação em enfermagem volta-se ao equilíbrio para a formação técnico-científica e humana, em consonância com os encaminhamentos das políticas educacionais em vigor.

\section{Paradigma ético-humanista: uma visão acadêmica}

Cada vez mais deparamo-nos com cobranças políticas e sociais no intuito de propiciar uma formação profissional que possibilite o estabelecimento de relações mais éticas e humanas. Segundo Matos (2006), tais relações, indo além do cumprimento dos princípios da bioética (beneficência, autonomia, não maleficência, justiça), requerem um comportamento profissional pautado no 'cuidado' com o ser humano, sendo este baseado no acolhimento, no respeito e no vínculo. A busca por uma formação humanística, portanto, deve-se a uma perspectiva alicerçada no homem e para o homem, em que são consideradas suas potencialidades criativas, respeitando as diferenças e individualidades e visando a condições de vida dignas.

A ideia básica aqui é a de que os valores, ou significados dos objetos, atos, ou eventos, os tornam emotivamente carregados, dotados de valências positivas e negativas e, assim, dotados de função. Os valores passam a exercer algum tipo de determinação, de controle não só sobre as escolhas mais decisivas ou sobre as relações interpessoais: eles atuam também sobre os órgãos e sistemas da machine humaine. Se, quando a pele de uma criança é espetada por um espinho ou por uma agulha, as estruturas sensoriais e a fibra nervosa reagem às propriedades físicas do estímulo, o sistema nervoso central, necessariamente, reage, também, aos significados ou valores que esse evento possui, graças à história pessoal dessa criança. Em resumo, o homem que o médico trata é o velho homem da Filosofia: o homem que é a "medida de todas as coisas", "criador de valores", exposto às forças da natureza, como um caniço açoitado pelo vento, "mas um caniço que pensa", como escreveu Pascal, e que se assusta (Pessotti, 1996, p. 446-447).

O autor acrescenta:

Tratar a machine humaine implica conhecer, ou pelo menos, admitir essa individualidade, até fisiológica, de cada homem. Em suma, nenhum médico consegue tratar só do corpo doente, ainda que o pretenda ou professe. Qualquer relacionamento entre pessoas é, em alguma medida, um encontro (mais ou menos harmônico) entre diferentes sistemas de valores e significados que cada uma delas atribui aos objetos, às ações, às palavras (Pessotti, 1996, p. 447). 
Tendo, pois, como pano de fundo as implicações de uma formação ética e humanística do profissional de saúde, trazemos à tona a análise dos discursos dos sujeitos do processo de pesquisa, realizada pelo método proposto por Bardin (1977), estando presentes os discentes e os docentes do curso de graduação em enfermagem, expondo sobre sua compreensão e atuação segundo o paradigma que entendem como ético-humanista.

Nesses discursos são analisados, além do entendimento desse olhar de formação, aspectos tais como métodos de ensino e inovações tecnológicas e pedagógicas, a existência do desenvolvimento ou promoção interdisciplinar, as formas e os manejos referentes ao relacionamento interpessoal, bem como a capacidade de negociação, mudança e trabalho em grupos, a partir dos quais emergiram categorias.

Com relação às categorias, elas foram elencadas seguindo a análise de conteúdo de Bardin (1977), conforme segue: totalidade/multidimensionalidade; interdisciplinaridade/disciplinaridade/dicotomia teoria-prática; relações interpessoais/competência interpessoal.

\section{Totalidade/multidimensionalidade}

Trata-se, pois, de assegurar, por meio de prática de cuidados, o indivíduo como ser integrante de uma complexa teia de relações, a continuidade da vida deste, do grupo social onde este se insere ou, mesmo, da própria vida da espécie.

A necessidade da ênfase na formação do enfermeiro segundo uma concepção de desenvolvimento total da pessoa, explicitando a ideia de dar valor às dimensões éticas e culturais, proporcionando meios de compreender o outro, na sua especificidade, e de compreender o mundo, é um fator abordado em nossa análise e cujo recorte subsequente ilustra esta questão:

Essa importância ético-humanista tem que ver na formação do aluno quando ele consegue observar o indivíduo como um todo (...); ele consegue perceber este indivíduo e inseri-lo em um contexto, seja ele social, econômico, tendo a visão do todo deste paciente, é por isso que é extremamente importante que o aluno tenha esta formação, para deixar de ver somente a doença que o paciente apresenta naquele momento, e o que levou este indivíduo a chegar nestas condições (Pl).

Para Behrens (2009), a forte influência do avanço paradigmático nas ciências levou a uma nova visão de mundo. Dessa forma, diz o autor, o grande desafio da visão totalitária do indivíduo, ou holística, está em superar o saber fragmentado que se instituiu com o positivismo no processo pedagógico. 
Capra (1982) nos diz que a nova visão da realidade baseia-se na consciência do estado de inter-relação e interdependência essencial de todos os fenômenos - físicos, biológicos, psicológicos, sociais e culturais. Tal visão, segundo esse autor, transcende as fronteiras disciplinares e conceituais, devendo ser explorada no âmbito de novas instituições.

Com relação ao exposto, podemos entender que a implementação efetiva de uma nova concepção de formação ainda caminha a passos lentos na medida em que busca, especialmente por meio de adequações curriculares, traçar novas estratégias que atinjam o propósito de formação esperado ou almejado. Tal perspectiva é evidenciada pelos sujeitos da pesquisa em sua percepção dessa dimensão ética e humanista no processo de formação do enfermeiro como docente...

(...) ela é um ideal de formação, porém acredito que como toda realidade tem lá sua própria dialética, na prática ainda estamos um pouco distantes da efetividade. (...) acredito que temos que preparar melhor nossos docentes, e não só eles mas também as próprias instituições de formação têm que se preparar nas suas condições tecnológicas, nas suas condições físicas, para que o ambiente de formação seja realmente um ambiente que tenha condições para efetivar esta percepção e torná-la algo mais concreto fora do seu próprio discurso (P2).

Mesmo sendo uma dimensão essencial, quando nos inserimos nas instituições como supervisores de estágio ou ensino clínico, percebemos que há uma dissonância entre o discurso ético-humanista "pregado" na academia e as exigências do mundo do trabalho (...). Então, para mim, essa dimensão ainda encontra-se incipiente nos serviços de saúde, o que distancia a academia da prática profissional do futuro enfermeiro (P3).

Acredito que esse contexto é muito pouco discutido e trabalhado dentro de sala de aula (P4).

Pra ser sincero, nunca ouvi falar de paradigma ético-humanista. A terminologia de ética é clara, a terminologia de humanização também, agora dizer que isso constitui um paradigma, pra mim, é uma novidade (P6).

...e como discente:

Penso que não há um paradigma predeterminado no processo de formação acadêmica (A2).

Na formação acadêmica, esse paradigma é abordado de forma direta e indireta (A3). 
Bom, professora, penso que a questão da ética (profissional) é pouco trabalhada na graduação de enfermagem, mesmo porque nos deparamos com vários profissionais da enfermagem, na prática, sem ética (A5).

De modo geral, as respostas apontam para os sujeitos inseridos no processo de formação e na prática, porém nos remetem ao (des)preparo desses profissionais para um amadurecimento capaz de servir como ferramenta para transformação da realidade dos serviços de saúde, bem como à política institucional, em que percebemos a necessidade de (re)pensar a concretização do discurso das IES por um ideário profissional em contraponto às imposições das instituições de saúde de onde a realidade de atuação emana.

A mudança de paradigma na assistência à saúde e, portanto, na formação desses profissionais, especialmente aqui mencionada a do enfermeiro, envolve a formulação de novos modelos conceituais, a criação de novas instituições e a implementação de novas políticas. Observamos, pois, a tentativa de adequação a esses parâmetros no processo de formação do enfermeiro, porém ainda distantes, como podemos perceber nas falas reproduzidas, de um contexto mais amplo que permeia em nossos tempos a sociedade de forma geral. Entendemos, portanto, que não se trata apenas de reescrever um projeto pedagógico ou alterar uma matriz curricular, mas de empreender forças às mudanças de atitudes e pensamentos de todos os envolvidos nesse processo, a fim de que tais forças convirjam para o entendimento do homem como um ser inteiro, total, holístico e multidimensional.

\section{Interdisciplinaridade/disciplinaridade/dicotomia teoria-prática}

Desde outrora, a humanidade se defronta com o desafio da fragmentação, como é o caso da grande especialização do conhecimento, que vem sendo estudada e criticada. Dessa crítica ao pensamento científico, tido como tradicional, outros caminhos vêm surgindo, sendo um deles o da interdisciplinaridade. É por esses novos caminhos, portanto, que vamos entendendo e contestando cada vez mais as ciências, especialmente a ciência médica, por meio do modelo biomédico, fortemente arraigado na educação em saúde.

As disciplinas ou os corpos de conhecimentos, segundo Luck (2007), foram construídos com base em um paradigma teórico-metodológico que norteou a determinação da visão especializada de mundo, centrado nas proposições de Descartes e Newton, combinando empirismo e lógica formal. Assim, a disciplinaridade, ou seja, o ensino por disciplinas fragmentadas, se dá mediante a aplicação dos princípios da delimitação interna, o foco no objeto próprio de análise, a decomposição de problemas em partes separadas e sua ordenação posterior, por meio do raciocínio lógico formal, 
caracterizado pela regra da exclusão do que é e do que não é. Dessa forma, podemos dizer que a disciplinaridade constitui uma visão limitada para orientar a compreensão e o entendimento da realidade tão complexa dos tempos atuais, bem como da atuação em seu contexto.

Em contraponto a isso, emerge a prática interdisciplinar, numa tentativa de superação da fragmentação e da linearidade, tanto no processo de ensino como no de aprendizagem.

Japiassu (1976, apud Rossi, 2004) afirma que a interdisciplinaridade é uma resposta sintomática da situação patológica em que se encontra, hoje, o saber. Complementa dizendo que o exagero das especializações conduz a uma situação de 'inteligência esfacelada', que produz um 'saber em migalhas'. A interdisciplinaridade propõe uma reformulação das estruturas de ensino superior, o que privilegia um ensino de interconexões, diferentemente da disciplinaridade, que, segundo Vilela e Mendes (2003, apud Rossi, 2004, p. 57), parte do preceito de disciplina como "uma progressiva exploração científica especializada numa certa área, limitada por fronteiras que, por sua vez, delinearão os objetivos materiais e formais, os métodos e sistemas, os conceitos e teorias; em resumo, o ensino de uma ciência".

Entendemos que o enfoque disciplinar nos cursos de graduação é resultado de uma postura científica que promoveu a excessiva especialização e fragmentação, o que resultou em alienação e depauperamento do ser humano. Por consequência, o conhecimento acaba sendo fragmentado pela própria estrutura universitária, dificultando o convívio na diversidade e tornando a prática profissional um grande desafio ao enfermeiro inserido nesse universo.

Em consonância, versam as falas a seguir:

Nós vemos dentro do curso disciplinas específicas para isso, nós temos ética e humanização, nós temos relações interpessoais, que preparam o aluno para ter esta visão (P1).

(...) há uma série de disciplinas que já vêm trabalhando esta questão de dimensionar a formação dentro de uma concepção ético-humanista, e nós temos as disciplinas de caráter social, as disciplinas humanas e, particularmente, a disciplina de relações interpessoais (P2).

Olha, eu não tenho conhecimento profundo de todas as disciplinas do curso... Domino bem a semiologia e a semiotécnica (teoria e ensino clínico) e estágio curricular supervisionado, então vou responder considerando essas duas. Na semiologia, seja teoria ou ensino clínico, essa concepção é difícil de ser abordada, já que a parte técnica é muito evidenciada (P3). 
Dou como exemplo a minha própria disciplina (fisiologia), que apesar de ser considerada uma disciplina básica, oferece várias oportunidades para tal valorização (P4).

No curso de enfermagem, tentamos valorizar este paradigma desde o $1^{\circ}$ período do curso, segundo os eixos e as disciplinas integrantes na matriz curricular (P5).

Se eu não conheço o paradigma, como eu posso ver estimulação disso no curso? (P6).

Podemos observar, por meio desses apontamentos, que sinais do paradigma inseridos no processo de formação são indicados como evidentes em disciplinas e nos estágios, exceto ao sujeito P6, que desconhece tal concepção. Trata-se de disciplinas que têm a intenção de dimensionar a formação, teórica ou prática, no direcionamento da interlocução ao longo da formação e que demonstram a relação pontual e direta com a prática e a relação desta com a teoria, com vistas ao futuro profissional.

Tendo em vista o exposto, acreditamos que existe ainda incipiência na aplicabilidade da metodologia interdisciplinar na realidade do ensino superior, porém há indícios de um encaminhamento para superação, seja quando nos atemos ao que propõem hoje as DCNs que direcionam os projetos pedagógicos dos cursos de graduação, seja nas estratégias de implementação, mesmo que embrionárias, em matrizes curriculares de instituições que almejem uma mudança concreta para o alcance real de um ideário de formação em enfermagem.

\section{Relações interpessoais/competência interpessoal}

As ações cotidianas da enfermagem, segundo Medeiros (2001), têm denotado a fragilidade de estudos capazes de compreendê-las em seu ato pedagógico, especialmente nos cursos de graduação. De características técnicas desde seu surgimento, a profissão é reconhecida por suas atividades práticas. Tal pragmatismo ao longo do percurso histórico em enfermagem caracterizou-se, até meados da década de 1970, por formar profissionais com excelência técnica em prol de um caráter crítico que pudesse garantir à profissão seu significado epistemológico crítico. Assim, o pensar, por um viés técnico, tornou-se um ato mecânico.

Segundo a mesma autora, das várias e intensas situações vivenciadas no processo de ensino-aprendizagem pode-se estabelecer que as interações sociais, tomadas como fato pedagógico em suas intervenções, promovem mecanismos nas relações interpessoais que eclodem na construção individual do conhecer.

De acordo com Del Prette (2007), quando nos propomos a refletir a temática das relações interpessoais em uma perspectiva sistêmica, a decom- 
posição do desempenho social em diversificados níveis de habilidades, supondo-as sempre em um contínuo e não em uma relação dita dicotômica, faz sentido apenas se entendermos o desempenho como conjunto de subsistemas do indivíduo em integração com seu ambiente. Assim, o ambiente não se refere apenas a situações específicas, mas também a contextos como os da família, da escola, da cultura e da sociedade. Trata-se de formar não só o enfermeiro, mas um enfermeiro cidadão, capaz de estabelecer em sua vida pessoal e profissional relações igualitárias, fraternas e amistosas.

Trazemos algumas falas dos sujeitos de nossa pesquisa que nos incitam a corroborar a indissociabilidade dos aspectos que envolvem o saber humano e seu processo de formação.

A gente percebe um amadurecimento do aluno (...) é um aluno mais atencioso, que realiza as coisas com mais critério (P1).

(...) nós percebemos algumas situações em sala de aula que os alunos já utilizam as competências, já se assumem nestas competências (...) nós percebemos como é que eles estão fazendo a transposição de toda a parte teórica desta disciplina (relações interpessoais) nas suas relações interpessoais dentro dos campos de estágio (...) já são capazes de tomar suas decisões, são capazes de fazer suas negociações, já têm um olhar crítico sobre as relações interpessoais da equipe (P2).

Como futuro gestor, esse profissional necessita mobilizar diversas competências no seu cotidiano para o bom andamento do processo de trabalho da enfermagem, e sem as relações interpessoais, essa mobilização pode não acontecer ou acontecer de maneira ineficaz (...) a disciplina de RI é um alicerce para que estas possam ser exploradas em maior profundidade (P3).

(...) no nosso curso, as aulas teóricas buscam preparar este indivíduo no seu contexto psicológico, na sua integração social e profissional, assim como no seu desempenho, fazendo com que se sintam funcionalmente competentes no contexto da cultura e dos sistemas de valores nos quais eles convivem (P4).

(...) a boa comunicação intrapessoal que eles têm que fazer, e isso proporciona o processo de crescimento (P6).

(...) é nos ensinado esse paradigma a cada aprendizado de técnica de enfermagem, cuidados de enfermagem, porque só poderemos oferecer um cuidado de qualidade se formos tanto éticos quanto humanos na realização deste (A3).

Nas situações de relações pedagógicas, as experiências vividas ricamente, na grande maioria das vezes, acabam por satisfazer formas mais 
efetivas de relacionamento, desencadeando construções de aprendizagem outrora inimagináveis.

Souza (2004) nos direciona para a percepção das relações que se estabelecem no processo educativo e o quão desgastadas estão, baseadas quase que somente no ensino de conteúdos fatuais, sem nenhum significado ou sentido para alunos e professores. Almeida (2001, apud Souza, 2004) nos fala das habilidades de relacionamento interpessoal, especialmente o olhar atento, o ouvir ativo e o falar autêntico, que podem ser desenvolvidas pelo professor, ao mesmo tempo que os alunos as desenvolvem. Esse desenvolvimento é possível, segundo a mesma autora, por meio do exercício cotidiano do 'olhar', do 'ouvir' e do 'falar', como atividades que vão além do que se vê na aparência, do significado das palavras ditas e de uma fala unilateral, que contém somente um ponto de vista.

(...) ver de novo, olhar o novo é um exercício imprescindível quando estamos interessados nas relações interpessoais. Isso porque muitas vezes nos habituamos à rotina da aula, guiando-nos por determinado formato que obscurece nosso olhar, "desativa" nosso ouvir e aliena nosso falar" (Souza, 2004, p. 48).

Num cenário de constantes mudanças, aprender a conviver continua sendo um grande desafio, fruto de uma história da humanidade marcada por conflitos e em que se torna difícil desestimular os preconceitos e hostilidades, resolver conflitos latentes ou emergentes, enfim, descobrir de forma progressiva o outro sem esquecer que ele é apenas humano, como você, como eu, como nós.

\section{Considerações finais}

Mas aprendi que, num hospital, por mais que ele seja bom, você passa a ser um número. Sofri muito com isso. Chega de manhã, o cara tem de dar banho em você e em mais trinta. Então ele me lava como se estivesse lavando um banheiro. É mais um número. Vira de um lado, vira do outro, e pronto. Isso não é só no hospital público, não, o outro hospital onde fiquei é particular, e caro. E lá teve um enfermeiro que, para lavar meu sovaco, me puxou pelo ferro ortopédico que tive de colocar no braço esquerdo. Quase morri de dor.

(Marcelo Fontes Nascimento Santa Ana, Marcelo Yuka, O Rappa, Veja, 2001)

É inadequada e gritante a forma como o profissional de enfermagem é retratado inúmeras vezes pelos clientes por ele assistidos. Como se não bastasse um tabu histórico que ainda prevalece na enfermagem relacionado com a opção ou o apelo sexual, ainda nos deparamos com situações como a 
relatada aqui, com a falta de respeito e de humanização do cuidado. Infelizmente, o fato narrado não está totalmente alienado da prática profissional exercida por muitos nos dias de hoje. Trata-se, tão somente, de esquecer para quem se faz, levando em consideração o fazer incessante, técnico exclusivamente e dentro de um período predeterminado.

Ao contrário do que se vê, está a tentativa, por meio da formação segundo um paradigma ético-humanista, de ensinar o humano a ser, novamente, humano. Nesse contexto, privilegiamos o que consideramos alicerce desse processo de formação: as relações interpessoais - relações essas que se estabelecem entre os pares e que se constituem fundamentais para o exercício profissional em enfermagem. Tal pressuposto é compactuado com os achados neste estudo e que comprovam a importância e a relevância dessa perspectiva de formação, em que a preocupação volta-se não só à competência técnica e científica, mas também à capacidade e à habilidade interpessoal que se adquire ou se desenvolve à medida que é trabalhada durante a graduação, e que constitui ferramenta indispensável ao exercício da enfermagem como profissão preocupada com o cuidado humano.

Remetendo-nos às categorias de análise advindas dos discursos dos sujeitos durante esta pesquisa, entendemos que estas refletem, ou melhor, clarificam a percepção do paradigma ético-humanista dentro do processo de formação. A primeira categoria, intitulada 'totalidade/multidimensionalidade', vai ao encontro do proposto pelas diretrizes curriculares quando prevê a formação voltada às diversas dimensões da relação indivíduo/sociedade e que contribui para a compreensão dos determinantes sociais, culturais, comportamentais, psicológicos, ecológicos, éticos e legais, envolvendo o ser cuidado em um contexto de vida e não de 'uma peça' doente e que necessite de reparos. Demonstra ainda os dilemas pontuados pela literatura entre a ênfase técnico-científica exigida pela sociedade e as reais necessidades para o alcance da saúde e do bem-estar do ser humano em uma perspectiva de qualidade de vida de quem é cuidado e qualidade de assistência prestada do cuidador.

Ainda alicerçados nas DCNs, entendemos a formação de indivíduos críticos e reflexivos como essencial à mudança da atual situação da enfermagem, concebendo a necessidade de conceber o indivíduo em suas diversas dimensões para pensar, fazer e ser, tendo os princípios de um paradigma ético-humanista como norteador. Porém, não se pode afirmar peremptoriamente que essa discussão finda-se aqui, já que este trabalho limita-se a uma única instituição, e a temática que aborda as convergências e divergências entre ensino e mundo do trabalho é de vasta abrangência.

A segunda categoria discorre sobre três fatores consonantes e dissonantes simultaneamente, mas que são capazes de incutir discussões extremamente relevantes e que permeiam o processo de formação e a maneira como 
essa formação é vista e sentida pelos sujeitos de nossa pesquisa. São eles: 'interdisciplinaridade/disciplinaridade/dicotomia teoria-prática'. Entendemos assim que, além da necessidade de mudança paradigmática das instituições formadoras e de saúde de modo geral, para o enfermeiro desenvolver a assistência de maneira ética e humanista no seu cotidiano deve haver coerência entre a sua trajetória acadêmica, o mundo do trabalho e as atitudes profissionais ao longo de seu percurso. Aqui encontramos uma lacuna significativa em nossa análise, quando percebemos que a interlocução entre teoria e prática existe ao longo da formação ou, pelo menos, há uma intencionalidade em fazê-lo, ao passo que tal interlocução se finda na medida em que esse profissional é inserido no mercado de trabalho.

Podemos entender que tentativas pessoais são realizadas no intuito de favorecer a atenção e a assistência de forma totalitária, integrando teoria e prática em uma perspectiva ética, crítica e reflexiva, porém diversos são os fatores dissonantes que apontam para outro caminho quando falamos de prática profissional, um caminho de maior produtividade e qualidade técnica.

Quando externalizamos a importância atribuída à qualidade técnica no campo de atuação profissional, emerge uma categoria que permeia intimamente o paradigma ético-humanista: as 'relações interpessoais/competência interpessoal'. As relações que se estabelecem entre os pares são refletidas nas ações cotidianas e caracterizam a singularidade e a complexidade humanas. Percebemos, pois, que a realidade de formação e de prática profissional dificulta a articulação do cuidado, culminando no retrocesso ao cartesianismo e, portanto, à prevalência de um pensamento que privilegia o conhecimento técnico-científico em detrimento do saber integral e multidimensional, ético e reflexivo, humano e questionador.

As relações interpessoais aqui emergem como poderosa ferramenta para veicular o cuidado em todos os seus domínios, como demonstram os participantes deste estudo, que consideram esta ferramenta um elemento facilitador do processo de trabalho e da formação do caráter individual e que pode, sim, ser desenvolvido durante o processo de formação.

De modo geral, o que esperamos hoje da formação é a atribuição de outros valores ao ensino, de forma que proporcione ao aluno o desenvolvimento da assistência digna, humana, tanto ao cuidador como ao ser cuidado, sem desmerecer absolutamente em nenhum momento a competência técnico-científica esperada na capacitação desse profissional. Ao mesmo passo, temos consciência de que esse paradigma ético-humanista e, portanto, tal perspectiva de formação ainda permanecem na inércia da grande maioria das estruturas universitárias e do mercado de trabalho no Brasil.

Há que se elucidar, nesse momento, que não procuramos, nesta pesquisa, defender o paradigma ético-humanista, mas demonstrar o que representaria tal opção, que ora se vê norteada pelas diretrizes curriculares 
nacionais, ora constitui uma possibilidade de incorporar novas formas de ver e ser no mundo.

Os resultados desta pesquisa propiciam uma série de reflexões sobre o processo de formação do enfermeiro e fornece subsídios, ainda que embrionários, que desafiam esse profissional. O princípio desses desafios ancora-se na maneira como se dá o processo de formação em um cenário que valoriza sobremaneira o aspecto técnico como elemento essencial para uma prática mecânica e, portanto, produtivista.

Vislumbro ainda novas possibilidades de desdobramentos das ideias aqui propostas, no sentido de repensar a formação em enfermagem que seja capaz de fundamentar-se em princípios pedagógicos que visem à totalidade do ser em formação e do ser assistido por esse profissional da saúde, deixando de lado o discurso para se tornar, efetivamente, algo em que valha a pena investir quando pensamos em quem formamos: a nós mesmos - o homem.

Tendo em vista, pois, a implementação de um projeto pedagógico que busca uma formação diferenciada, de acordo com um paradigma ético-humanista e o entendimento dos sujeitos quanto à importância desse paradigma na formação, a dúvida agora se concentra em determinar em que medida isso se concretiza aos olhos daquele a quem o cuidado se faz: o paciente. Nessa perspectiva, deixamos como sugestão que outras possibilidades de abordagem sejam promovidas no intuito de refletir e fortalecer a prática profissional do enfermeiro.

\section{Notas}

${ }^{1}$ Instituto Federal do Paraná, Curitiba, Paraná, Brasil.

Mestre em Educação pela Universidade Tuiuti do Paraná. <josiane.ferla@ifpr.edu.br> Correspondência: Rua Professor Sebastião Paraná, 632, apto. 13, CEP 80320-070, Vila Izabel, Curitiba, Brasil.

2 Neste caso, 'reparo' significa reajuste, conserto. Como exemplo, podemos considerar uma máquina que tem uma peça danificada e pode ser consertada, reparada, reajustada. Assim também são os sistemas, passíveis de serem rearranjados, reorganizados no sentido de seu melhor funcionamento. 


\section{Referências}

BARDIN, Laurence. Análise de conteúdo. Lisboa, Portugal: Edições 70, 1977.

BEHRENS, Marilda A. O paradigma emergente e a prática pedagógica. 3. ed. Petrópolis, RJ: Vozes, 2009.

BEHRENS, Marilda A.; GISI, Maria de L. Educação em Enfermagem: novos olhares sobre o processo de formação. Curitiba: Champagnat, 2006.

BERGER, Maria V. B. Educação transpessoal: integrando o saber ao ser no processo educativo. 2001. 371 f. Tese (Doutorado em Educação) - Universidade Estadual de Campinas, São Paulo, 2001.

BRASIL. Ministério da Educação. Conselho Nacional de Educação. Câmara de Educação Superior. Resolução CNE/CES n. 3, de 07 de novembro de 2001. Institui as diretrizes curriculares nacionais do curso de graduação em enfermagem. Diário Oficial da República Federativa da União, Brasília, 9 nov. 2001. Seção 1, p. 37.

Ministério da Educação. Conselho Nacional de Educação. Lei de Diretrizes e Bases da Educação Nacional. Lei n. 9.394, de 20 de dezembro de 1996. Disponível em; $<$ www.planalto.gov.br/ccivil_03/leis/19394. htm >. Acesso em: 1 set. 2009.

Ministério da Saúde. Conselho Nacional de Saúde. Comissão nacional de ética em pesquisa. Resolução 196/96. Normas regulamentadoras envolvendo seres humanos. Brasília: Ministério da Saúde, 1996b.

CAMARGO, Maria C. Von Z. A. O ensino da ética médica e o horizonte bioética. 1996. Disponível em: <www.cfm.org.br/revista/ 411996/ensin2.htm>. Acesso em: 1 set. 2008.

CAMPOS, Rosana T. O. Reflexões sobre o conceito de humanização em saúde. Revista Saúde em Debate, Rio de Janeiro, v. 27, n. 64, p. 123-130, maio/ago. 2003.
CAPRA, Fritjot. O ponto de mutação: a ciência, a sociedade e a cultura emergente. São Paulo: Cultrix, 1982.

CORTELAZZO, Iolanda B. C. Colaboração, trabalho em equipe e as tecnologias de comunicação: relações de proximidade nos cursos de pós-graduação. 2001. 183 f. Tese (Doutorado em Educação) - Faculdade de Educação da Universidade de São Paulo. São Paulo, 2001.

DEL PRETTE, Almir. Psicologia das relações interpessoais: vivências para o trabalho em grupo. 6. ed. Petrópolis: Vozes, 2007

DEMO, Pedro. Pesquisa: Princípio científico e educativo. São Paulo: Cortez, 1990.

GEOVANINI, Telma et al. História da Enfermagem: versões e interpretações. 2.ed. Rio de Janeiro: Revinter, 2005.

GHEDIN, Evandro L. Professor reflexivo: da alienação da técnica à autonomia da crítica. In: PIMENTA, Selma G.; GHEDIN, Evandro (Orgs.). Professor reflexivo no Brasil: gênese e crítica de um conceito. 3. ed. São Paulo: Cortez, 2002. p. 129-150.

KHUN, Thomas S. A estrutura das revoluções científicas. 9. ed. São Paulo: Perspectiva, 2007.

KRUSE, Maria H. L. É possível pensar de outro modo a educação em Enfermagem? Escola Anna Nery Revista de Enfermagem, Rio de Janeiro, v. 12, n. 2, p. 348-52, 2008.

LUCK, Heloísa. Pedagogia interdisciplinar: fundamentos teórico-metodológicos. 15. ed. Petrópolis: Vozes, 2007

LUDKE, Menga; ANDRÉ, Marli E.D.A. Pesquisa em Educação: abordagens qualitativas. São Paulo: EPU, 1986.

MATOS, Mariângela S. Análise do perfil dos alunos e da dimensão ético-humanística na 
formação de cirurgiões-dentistas em dois cursos de odontologia da Bahia. 2006. $318 \mathrm{f}$. Tese (Doutorado em Educação) - Universidade Federal da Bahia. Salvador, 2006.

MEDEIROS, Roseana M. Construção de competências em enfermagem. Caxias do Sul: EDUCS, 2001.

MIZUKAMI, Maria G. N. Ensino: as abordagens do processo. São Paulo: EPU, 1986.

MORAES, Maria C. B. O paradigma educacional emergente. São Paulo: Papirus, 1997.

PESSOTTI, Isaías. A formação humanística do médico. Medicina Ribeirão Preto, São Paulo, v. 29. p. 440-448, out./dez. 1996.

ROSSI, Elaine. Ensino e saúde: práticas educacionais multidisciplinares. Curitiba: Editora Maio, 2004.

SANTOS, Boaventura S. Um discurso sobre as ciências. 5.ed. São Paulo: Cortez, 2008.

SCHIRR, Fabíola. Ser educador em enfermagem: limites e possibilidades na atuação profissional. 2006. Dissertação (Mestrado em Educação) - Universidade Tuiuti do Paraná. Curitiba.
SCHMIDT, Elizabeth S. Currículo: uma abordagem conceitual e histórica. Ponta Grossa, 2003. Disponível em: <www.uepg.br/ propesp/publicatio/2003/06.pdf > . Acesso em: 10 dez. 2009.

SCHÖN, D. A. Educando o profissional reflexivo: um novo design para o ensino e a aprendizagem. Tradução de Roberto Cataldo Costa. Porto Alegre: Artmed, 2000, 256 p.

SOUZA, Vera L. T. Relações interpessoais e universidade: desafios e perspectivas. In: ALMEIDA, Laurinda R.; PLACCO, Vera M. As relações interpessoais na formação de professores. 2. ed. São Paulo: Ed. Loyola, 2004

WALDOW, Vera R. Cuidado humano: o resgate necessário. 3. ed. Porto Alegre: Sagra Luzzatto, 2001.

ZANETTE, Maria V. Projeto político pedagógico: movimento contínuo e emancipatório. 2003. 155 f. Dissertação (Mestrado em Educação e Cultura) - Universidade do Estado de Santa Catarina, Florianópolis, 2003.

Recebido em 15/03/2011

Aprovado em 18/10/2012 